\title{
Higher order thinking skills competencies required by outcomes-based education from learners
}

\author{
MM Chabeli, \\ School of Nursing, University of Johannesburg
}

\section{Keywords:}

Outcomes-Based Education (OBE); critical thinking, reflective thinking, creative thinking, dialogic / dialectic thinking, decision making, problem solving and emotional intelligence

\section{Correspondence address:}

Prof Mary Chabeli

School of Nursing

University of Johannesburg

POBox 524

Auckland Park

2006

Tel : (011) 489-2655/2580

Fax : (011) 489-2257

Email:mch@edcur.rau.ac.za

\section{Abstract: Curationis 29(3): 78-86}

Outcomes-Based Education (OBE) brought about a significant paradigm shift in the education and training of learners in South Africa. OBE requires a shift from focusing on the teacher input (instruction offerings or syllabuses expressed in terms of content), to focusing on learner outcomes. OBE is moving away from 'transmission' models to constructivistic, learner-centered models that put emphasis on learning as an active process (Nieburh, 1996:30). Teachers act as facilitators and mediators of learning (Norms and Standards, Government Gazette vol 415, no 20844 of 2000). Facilitators are responsible to create the environment that is conducive for learners to construct their own knowledge, skills and values through interaction (Peters, 2000). The first critical cross-field outcome accepted by the South African Qualification Framework (SAQA) is that learners should be able to identify and solve problems by using critical and creative thinking skills.

This paper seeks to explore some higher order thinking skills competencies required by $\mathrm{OBE}$ from learners such as critical thinking, reflective thinking, creative thinking, dialogic/dialectic thinking, decision making, problem solving and emotional intelligence and their implications in facilitating teaching and learning from the theoretical perspective. The philosophical underpinning of these higher order thinking skills is described to give direction to the study. It is recommended that a study focusing on the assessment of these intellectual concepts be made. The study may be qualitative, quantitative or mixed methods in nature (Creswell 2005).

\section{Introduction}

Outcomes-Based Education is a learnercentred, results-oriented approach to learning. Teachers and learners focus on the desired end results of each learning process which will be continuously assessed to ascertain whether they are making any progress. Focus is also on the instructive and learning processes that will guide the learners to these end results. Teachers are required to use the learning outcomes as a focus when they make instructional decisions and plan their lessons, and to create the learning environments which are inviting, challenging, stimulating, motivating, supporting, guiding and promoting the culture of lifelong learning (Van der Horst \& McDonald, 1997:7)

The most crucial question to be asked by a graduate from an OBE approach to teaching and learning is: "Will I be able to use what I have learnt in the working world, that is, outside school? Will I 'fit the purpose' of the educational programme? Will I be able to make the difference, make reasonable contributions in the area of choice? How will I contribute towards the growing economy of the country? All these questions focus on the applied competence of the learner. Applied competence refers to the overarching term for three interconnected kinds of competence. The practical competence where the learner demonstrate, in an authentic context, consideration of a range of possibilities for action, make considered decisions about which possibilities to follow and perform the chosen action. Practical competence is 
grounded in foundational competence where the learner demonstrates an understanding of the knowledge and thinking that underpins the action taken, and integrates it through reflexive competence. Reflexive competence is when the learner demonstrate the ability to integrate or connect performance and decision,making with understanding and with the ability to adapt to change and unforeseen circumstances and to explain the reasons behind these adaptations (Norms and Standards for Educators Government Gazette No. 20844, Feb. 2000:10).

Inherent to the learner who demonstrates applied competence from an OBE programme is critical thinking skills. There has been a world wide debate as to the meaning of critical thinking in relation to other higher order thinking skills such as reflective thinking, creative thinking, dialogic and dialectic thinking and emotional intelligence (Paul, 1993: Goleman, 1998:3, Brookfield, 1987:207). Varied perspectives on critical thinking exist in different contexts. Critical thinking is a complex behavior which is much needed in practice and for personal survival yet to date, there is no single, simple definition for it (Wilkinson, 1992:24). Critical thinking is an empowering activity through which comes personal and professional growth. Learners in general and nurse learners in particular need critical thinking because they work in an unpredictable and diverse environment where they are expected to come up with solutions, make rational decisions or solve unique and complex problems (Edwards, 2003: 1 142).

The philosophical basis of critical thinking and other related higher order thinking skills is a constructivistic approach to teaching and learning. Constructivistic theories argue that knowledge is constructed by individuals, and not passively acquired. The learner assumes self-directed learning with emphasis on active participation, critical enquiry, self-regulation and selfassessment abilities. Independence and individuality in constructing meanings should challenge the learner's comprehension as a result of new learning encounters. According to educationists nationally and internationally, critical thinking is the core cross-field learning outcome of all educational programmes that will enable learners to solve problems in their specific learning areas (Van der Horst and McDonald, 1997:217). However, critical thinking cannot be taught in isolation. It is well integrated in a dynamic domainspecific knowledge base. Critical thinking includes more than just the intellectual domain of human functioning. It is supported by the affective dispositions and other domains such as the creative, reflective and emotional domains.

\section{Problem statement}

Over decades, a widespread concern over the implementation of a relevant and accountable curriculum in South Africa was made nationally and internationally. South Africa was faced with challenges in education such as the provision of equal access to schools, equal educational opportunities, irrelevant curriculum, inadequate facilities and resources, the enrolment explosion and inadequately trained teaching staff. The traditional education practice encouraged rote learning, passiveness of learners.

The curriculum was exam-driven, content-based, rigid and non-negotiable. Teachers were responsible for learning instead of learners taking responsibility for their learning. Motivation depended on the personality of the teacher.

Emphasis was on what the teacher hopes to achieve and not on the outcomes, that is, a successful demonstration of learning that occurs at the culminating point of a set of learning experiences. What the learner is able to do, synthesize and apply successfully at the end of all formal instruction (Van der Horst \& McDonald, $1997: 5,21,27)$. It was to overcome these obstacles to learning that the country opted for the outcomes-based education to teaching and learning so that learners could be engaged actively in their learning to acquire and demonstrate critical thinking, creative thinking, reasoning, reflective thinking skills in order to be able to provide the best practice.

\section{The purpose and objectives of the paper}

The paper seeks to explore higher order thinking skills competencies and their implications for teaching and learning as required by the Outcomes-Based Education from learners in South Africa, and to make recommendations for further research.

\section{The assumptions of the researcher}

It is the researcher's believe that higher order thinking skills such as critical thinking, creative thinking, reflective thinking, dialogic / dialectic thinking, decision making, problem solving and emotional intelligence form the hallmark of outcomes-based education. They form the glue to effectively harness all the components of the outcomes-based education approach to learning. These thinking skills contribute to the best practice and lifelong learning.

\section{Method}

A theoretical exploration of relevant literature was made to describe the relationship of critical thinking to the stated higher order thinking skills and their implication to teaching and learning was made. First, a conceptual definition of critical thinking as one of the major learning outcome of any educational programme is made, followed by a description of the philosophical underpinning of the stated higher order thinking skills and a description and their implications. Lastly a recommendation for further research is made. Theoretical validity is ensured by making use of the relevant literature (Mouton, 1996).

\section{Conceptual definition of critical thinking}

The definition of critical thinking has been a concern to most authors. Its clarification has been under scrutiny for many years. However, critical thinking is contextually used to apply basic core knowledge, skills and attitudes to each situation (Wilkinson (1992:21). Oermann (1998:322), a renowned nurse author in critical thinking, stated that clinical nursing education occurs in a dynamic, complex and challenging situation where nurses are expected to use critical thinking as a fundamental principle to guide their rational decision-making process and clinical judgment logically in a systematic manner. Nurse authors adopted a definition of critical thinking as adapted from the American Philosophical Association's (APA) Delphi study who understand critical thinking to be purposeful, self-regulatory judgment which results in interpretation, analysis, evaluation, inference, as well as explanation of the evidential, conceptual, methodological, criteriological or contextual considerations upon which 
that judgment is based. Critical thinking is essential as a tool of one's personal and civic life. The ideal critical thinker is habitually inquisitive, well informed, trustful of reason, open-minded, flexible, fair-minded in evaluation, honest in facing personal biases, prudent in making judgments, willing to reconsider, clear about issues, orderly in complex matters, diligent in seeking relevant information, reasonable in the selection of criteria, focused in inquiry, and persistent in seeking results which are as precise as the subject and the circumstances of inquiry permit. Educating good critical thinkers means working toward this ideal. It combines developing critical thinking skills with nurturing those dispositions which consistently yield useful insights and which are the basis of a rational and democratic society (Facione, 1990:2).

This definition characterizes the daily functioning of a professional nurse responsible and accountable for own actions, omissions and commissions. The researcher agrees with the APA definition of critical thinking since nursing is goal directed. Nurses have to deal with the lives of the clients, sick or well. They therefore have to continuously seek reasons for their thoughts, actions and feelings, develop criteria and principles that effectively justify their value judgments by asking relevant and challenging questions, questioning assumptions, assessing, investigating, inquiring and solving complex health care problems of culturally diverse patients (Oermann, 1998:322; Wilkinson, 1992:9, 25; Edwards, 2003: 1 144; Spelic; Parsons; Hercinger; Andrews; Parks \& Norris, 2001:27; Beckie; Lowry; \& Bamett 2001:18; Facione \& Facione, 1996). Bandman \& Bandman, 1988:5, 6) define critical thinking as rational examination of ideas, inferences, assumptions, principles, arguments, conclusions, issues, statements, beliefs and actions. This examination covers scientific reasoning (inductive and deductive), including the nursing process where decision making and problem solving of controversial issues are addressed. To elaborate on this definition, Bandman and Bandman noted that critical thinking is reasoning in which nurses analyze the use of language, formulate problems, clarify and explicate assumptions, weigh evidence, evaluate conclusions, discriminate between good and bad arguments, check inferences for plausibility and seek to justify those claims, believes, decisions, facts and values that result in credible beliefs and actions.

Critical thinking is reflective in that one does not jump to conclusions or make hurried decisions but takes the time to collect evidential information, think the matter through in a disciplined manner, weigh facts, make conclusions and consider alternatives. Critical thinkers will explore the thinking that underlies emotions and feelings, suspend judgments when sufficient evidence is lacking, develop criteria for evaluation and applies them fairly and accurately and evaluates the credibility of sources used to justify beliefs. Critical thinkers make interdisciplinary connections and uses insights from one subject to illuminate and correct other subjects, distinguish facts from ideals, examine assumptions that underlie thoughts and behavior, distinguish the relevant from the irrelevant and the important from the trivial, makes plausible inferences and distinguishes conclusions from the reasoning that supports them and seek out evidence and gives evidence when questioned.

Critical thinking is rational, reasonable, outcomes-directed, purposeful mental activity involving clarifying ideas and evaluating the credibility of sources to make accurate clinical nursing judgments. It is both an attitude and a reasoning process using facts and observations to draw conclusions rather than prejudice, preferences, self-interest or fears. It is driven by enthusiasm and inquiry mind of the learner who engages in constant evaluation and re-evaluation, selfcorrecting and striving to improve own learning situations. Critical thinking involves open- and fair-mindedness in the manner that critical thinkers are willing to consider other perspectives. Learners must be knowledgeable and encourage dialogue which is handled in a logical manner in which more than one frame of reference can be used in an argument (Alfaro-Lefevre, 1999:9, 11).

\section{Philosophical foundation of critical thinking}

Philosophy is a field of study in pursuit of wisdom or knowledge especially of ultimate reality or of general causes and principles (The Little Oxford Dictionary of current English 1986). The concern is with philosophy as a mode of thinking and as a framework for thinking to guide the study (Paul, 1993:405). Philosophy is an art rather than a science, a discipline that formulates issues that can be approached from multiple points of view and invites critical dialogue and reasoned discourse between conflicting viewpoints. Philosophy is steeped in dialogue and dialectical thought. Critical thought and discussion are its main instruments for learning. This discipline in the mode of thinking characteristic of philosophy has roots in the ideal of learning to think with a clear sense of the ultimate foundation of one's thinking, of the essential logic of one's thought, and of significant alternative, competing ways of thinking (Paul 1993:405, 406).

Paul (1993:406,407,410) state that to think philosophically is liberating. It is to know the foundation of liberalism compared to those of conservatism. Philosophical thinking is necessary to freedom of thought and action. Freedom of thought and action are good in themselves and should be given a high priority in teaching and learning. It is precisely this philosophical underpinning that gives a framework for critical thinking since the basis of critical thinking is dialogic and dialectic in nature focusing on cognitive abilities and affective disposition (Facione, PA; Sanchez; Facione, NC \& Gainen 1995:10; Brookfield, 1987:12; Paul, 1993:406; Kamin; O’Sullivan; Younger \& Deterding 2001:27). Although the importance of critical thinking in education emerged as early as 1950's as a way of improving learning (Ignatavicius, 2001:37), the concept can actually be traced back to some Greek philosophers such as Socrates, Plato and Aristocle.

\section{Socrates (469-399 BC)}

Socrates was a Greek philosopher and a teacher. He taught by questioning his listeners and showing them how inadequate their answers were. He embraced the critical questioning attitude by asking critical and reflective questions sequentially until the response was arrived at. The questioning process took the form of dialectic philosophic conversation which became known as the Socratic method based on questioning that seek clarification, the probing of assumption, reasoning, seeking evidence to justify claims, seeking implications and consequences (The world book encyclopedia 1995 vol 18). However, Socratic questioning is flexible in that the 
questions asked at any given point will depend on what the learners say, what ideas the teacher wants to pursue. Generally, Socratic questions raise basic issues, probe beneath the surface of things and pursue problematic areas of thought (Paul, 1993:418). Nurses deal with unique complex, ill-structure problems in clinical nursing education and thus it is imperative that one of the integral roles of the nurse educator is to use Socratic questioning methods to encourage critical thinking of learners during the assessment of clinical situations rather than memorization of facts alone to arrive at rational clinical decisions and solve problems amicably. Authors believed "Socratic questioning and debates during dialogic and dialectic discussions will promote critical thinking (Oerman; Truesdell \& Ziolkowski 2000:155,156).

\section{Aristotle (384-322 BC)}

Aristotle, also a Greek philosopher, an educator and scientist, was one of the greatest and most scholarly and influential thinkers in western culture. Aristotle and his teacher Plato are considered to be the two most important of all the ancient Greek philosophers. Aristotle declared that a human being is "the rational animal" who is to reason. Thus, according to Aristotle, a happy life for human beings is a life governed by reasoning. Aristotle was the first philosopher to analyze the process whereby certain propositions can be logically inferred to be true from the fact that certain other propositions are true. In his writings, Aristotle considered summaries, arguments, criticisms and further developed all the rich intellectual tradition that he had inherited. He believed that there is a relationship between thinking and the intellect (The world book encyclopedia (1995: volume 1). The three Greek philosophers set standards in critical inquiry, problem solving, theory construction and reasoning (Kamin et al 2001:27).

\section{Piaget and Vygotsky}

Piaget (1954) is regarded as the first 'constructivist' in the field of learning. Piaget began his research into cognitive development in the 1920's. His interest lay in the intellectual changes that occur in the child's pattern of thought: Piaget's argument is that the child cannot learn simply by 'taking in' knowledge through the senses passively, nor is the mind of the child an empty vessel to be filled with knowledge. The child's intellectual development takes place through continuous engagement in active construction and deconstruction of knowledge through interaction with the environment. Piaget is of the opinion that curiosity is a vital overflow, an expression of an abundant organic energy, a physiological uneasiness that leads a child to get "into everything" - to be reading, packing, pounding and prying inquisitiveness.

The notion of active construction and deconstruction of knowledge through interaction with the environment is also echoed by other constructivistic theories such as (Vygotsky 1963; Ausubel 1968). A number of constructivist tenets put emphasis on the learning-centered orientation to learning, teaching and assessment. The constructivists believe that adult learners' prior knowledge is a valuable resource to be harnessed to enhance meaningful learning; that learning is an active process of constructing knowledge information that is exposed to the learner; and that teaching is about learning how learners conceptualize phenomenon and aligning such conceptions with those of the experts in the field in a cooperative and agreeable manner. The learning-centered orientation teaching and learning should be reflected in the assessment activities that will enable learners to be critical thinkers to manage practice and face real life challenges with confidence.

\section{Dewey}

Dewey (1933:36), also one of the philosophers, state that every living creature, while it is awake, is in constant interaction with its surroundings. Dewey (1933:38) observed that without curiosity, intellectual activity would be feeble and intermittent through lack of stuff for its operations. Lack of a questioning attitude would be a burden, and would dull the sharp edge of the learner's inquiry spirit (Dewey, 1933:40; Paul, 1993).

Critical thinking is dialogic and dialectic in nature. Teaching and assessment for critical thinking should focus on stimulating the learners' inquiry mind and intellectual development (Brookfield, 1987:12; Paul, 1993:427; Staib, 2003:501; Dewey, 1933:37; Beyer, 1988; McDonald \& Van Der Horst, 1997:217; Oerman et al 2000:155).
Based on this philosophical underpinning, nurse educators are challenged to focus on the teaching and assessment of the learner's ability to make rational clinical decisions and solve problems unique to individual patients. They should present real life situations to the learner to enable the learner to make meaningful connection of the existing conception to the new situation presented. Involve learners in critical dialogue and reasoned discourse between conflicting viewpoints. The assessor should ask critical and reflecting questions for learners to be able to engage in critical thought as they defend their reasoning and seek clarification. Encourage learners to defend their reasoning and justify their decisions and actions based on more evidence. Encourage learners to critically examine controversial issues, paraphrase, summarize for better understanding. By so doing the nurse educator will be able to judge how learners have increased their conceptual understanding of the content taught or experienced. The discussion of the philosophical foundation of critical thinking forms a solid ground for the debate of critical thinking being closely related to other related higher order thinking concepts such as creative thinking, reflective thinking, dialectic / dialogic thinking, decision making, problem solving and emotional intelligence.

\section{Debates pertaining to concepts closely related to critical thinking to elucidate the relatedness}

Critical thinking is sometimes contrasted with creative thinking, reflective thinking, dialectic thinking decision making, problem solving and emotional intelligence (Bailin; Case; Coombs \& Daniels 1999:288; Paul, 1993:101-146; Brookfield, 1987:114; Facione, A 1998:10; Wilkinson, 1992:9 \& Sale, 1997:4). A brief discussion on the relationship of critical thinking with these concepts will be made.

\section{Creative thinking and critical thinking}

Arguments are found in the literature regarding higher order thinking and how they interrelate to each other. Creativity, according to Paul (1993:101, 102, 103), masters a process of 'making' or producing, and criticality is a process of 
'assessing' or 'judging'. Paul argues that a thinking mind must virtually simultaneously produce and assess, make and judge that making. Paul maintains that the meaning of the two concepts overlap and feed into each other. They are inseparable, integrated and unitary. They are interwoven into one seamless fabric. They have an intimate relationship since all thinking that is properly called "excellent" combines critical and creative thinking in an intimate way. Whenever our thinking excels, it does so because we succeed in designing or engendering, fashioning or originating, creating or producing results and outcomes appropriate to our ends in thinking. It has, in a word, a creative dimension in that nurses continuously design, engenders, fashion or originate ideas, thoughts and feelings for the benefit of the client. It is important that we must continuously monitor and assess how our thinking is going, whether it is plausibly on the right tract, whether it is sufficiently clear, accurate, precise, considerate, relevant, deep or broad for our purposes. When the mind is not systematically and effectively embodied in intellectual criteria and standards, it is not disciplined in reasoning things through, in figuring out the logic of things, in reflectively devising a rational approach to the solution of problems or in the accomplishment of intellectual or practical tasks, that mind is not "creative. Criticality and creativity have an intimate relationship in the ability to figure things out. There is a natural marriage between them (Paul, 1993:102).

The notion of the interrelatedness of critical thinking and creative thinking is supported by many authors. Bailin et al, (1999:288) contends that creative thinking require the exercise of judgment based on critical thought. One may think critically while engaged in creative thinking. Similarly, one may need to be creative in thinking critically about problems and issues. Critical thinking often requires imagining possible consequences, generating original approaches and identifying alternative perspectives. Thus creativity plays an important role in thinking critically. Creative thinking involves the ability to establish new relationships and concepts and find new solutions to problems while critical thinking is goal-orientated, purposeful thinking that involves a number of skills such as evaluating the credibility of sources, making inferences, and clarifying ideas. It is an important intellectual skill and is essential to making good clinical judgments (Wilkinson, 1992:9). Although critical thinking is regarded as being evaluative and judgmental based on appropriate standards and criteria, Johnson (in Bailin et al 1999:188) assert that critical thinking plays an integral part in creative thinking and creative thinking is pivotal to critical thinking. Sale (1997:4) asserts that creative thinking aims at the 'generating process' that requires the process of analyzing, comparing and contrasting, making interpretations, inferences and evaluation, in short, critical thinking. The two concepts are interrelated and intertwined. It therefore becomes important during the facilitation of critical thinking of nurse learners to urge them to be creative in their practice.

To facilitate the development of creativity, Parnes (in Van der Horst and McDonald, 1997:222) urges teachers to start with a fuzzy problem or objective or a question which needs to be answered. Collect facts by analyzing the fuzzy problem and different key concepts are identified. Identify and reformulate the problem considering various angles using various action verbs. Encourage learners to generate numerous ideas and produce various alternative potential solutions to the problems using teaching strategies such as brainstorming, quiz, role playing, debate etc. The learners should devise different options for the solutions of problems selected and organized. Ways of measuring and comparing the different possible solutions are identified. At this stage the teacher should emphasize logical thinking and logical argumentation to stimulate creativity. Communicate the developed action plan to all the people involved.

\section{Reflective thinking and critical thinking}

The word 'reflective' comes from the Latin word "reflectere", meaning to bend back, casting back, introspecting, retrospecting, deliberative, willing, feeling, understanding and mediating. Thinking is defined as a mental activity, cognitive, conception, conative, mediating, pondering, willing, feelings, understanding and imagining (Dictionary of Philosophy, 1981). Ennis (1985:45), one of the prominent proponents of critical thinking, provided an expanded definition of critical thinking as a reflective and reasonable thinking that is focused on deciding what to believe or do. This definition is a practical activity of deciding what to believe or do in a practical situation. It includes formulating hypotheses, questions, alternatives based on the reflective dimension of the existing conception. Critical thinking and reflective thinking are not exercised in a vacuum (Dewey, 1933:153; Brookfield, 1987:23). They are developed and refined in active inquiry through a process of reflective analysis and synthesis with informed action. Critical and reflective thinkers develop a reflective skepticism in that they do not take for granted the universal truth of some statements, policy or justification simply because of the authority ascribed to the source of this supposed truth. They are wary of individuals who uncritically accept an innovation, change or new perspective simply because it is new. Reflective skepticism is, according to Brookfield (1987:21, 22, 23), a major affective outcome of critical thinking since claims for the universal validity and applicability of an idea or practice must be subject to a careful testing against each individual's experience. Skepticism is not synonymous with negativism. It means questioning what might otherwise be taken for granted or summarily rejected (Beyer, 1988:61).

The idea of reflective learning is closely related to that of critical thinking. Boyd and Fales (1983:100) define reflective learning as the process of internally examining and exploring an issue of concern, triggered by an experience, which results in a changed conceptual perspective. On the other hand, Boud, Keogh and Walker (1985:3) view reflection as a generic term for those intellectual and affective activities in which individuals engage to explore their experiences in order to lead to new understandings and appreciation. There is a close connectedness and interconnectedness of critical thinking and reflective thinking in that critical thinking involves a reflective dimension encompassing both the cognitive and affective disposition with the aim of developing a changed perspective. They are both triggered by inner discomfort, meaning, uncomfortable thoughts and feelings that urges one to act (Brookfield, 1987:14, 24; Gravett, 2001:24; Chabeli, 2001:107). Teachers should consider use of reflective journals, videos, experimental and experiential learning that 
will promote reflection on experiences. Teaching strategies that promote pondering and contemplation should be used (Quinn, 2000:64).

\section{Dialectical / dialogical thinking and critical thinking}

Dialectical / dialogical thinking is closely related to critical thinking. According to Brookfield (1987:12,13), dialectical thinking is viewed as a particular form of critical thinking that focuses on the understanding and resolution of contradictions. Dialectical thinkers engage in a continual process of making judgments about aspects in life, identifying the general rules implicit in these judgments and modifying the original judgments in light of the appropriateness of these general rules. Deshler (in Brookfield, 1987:13) contends that dialectical thinking is thinking which looks for, recognizes and welcomes contradictions as a stimulus to development. The relatedness of dialectical thinking and critical thinking is that critical thinking involves more than cognitive activities such as logical reasoning or scrutinizing arguments for assertions unsupported by empirical evidence. Thinking critically involves recognizing the assumptions underlying beliefs and behaviors. One can give justifications for one's ideas and actions through dialectical discourse. Dialectical thinking encourages learners to reason back and forth between their own ideas, thoughts and feelings, that is, learners reason their way to knowledge (Paul, 1993:333).

The word dialogue comes from the Greek word dia and logos. Dia means 'two', a connection of 'between, 'across' or 'through' and hence can apply to more than two connotations. Logos means 'word', 'speech', 'thought', 'reason' and 'judgment'. Dialogue is summarized by Burbules (in Gravett, 2001:35) as a kind of social relation that engages its participants. A successful dialogue involves a willing partnership and cooperation in the face of likely disagreements, confusion, failures and misunderstandings. Persisting in this process requires a relation of mutual respect, trust, and concern. Part of the dialogic interchange often must relate to the establishment and maintenance of these bonds. The substance of this interpersonal relation is deeper, and more consistent than any particular communicative form it might take. It is envisaged that dialogic process implies cooperative and reciprocal inquiry by putting forth questions, responses, redirections and building statement that form a continuous and developmental sequence. Dialogue is exploratory and interrogative for the purpose of breaking through to new insight (Gravett, 2001:36). Like critical thinking, dialogue is marked by a sharing attitude, respect, mutual trust, commitment, willingness and openmindedness.

Dialogue drives the learner-centered approach to teaching and learning. It encourages deep approach to learning because learners are involved and engaged in a search for meaning and understanding through active participation in exploratory discussions, debates, brainstorming, projects, workshops, case studies and so forth. The content should be taught in integrated wholes and related to other knowledge (Quinn, 2000:183). Dialogue and dialectic thinking should be encourage from lower classes and allow learners to grow with this culture of stimulating higher order thinking.

\section{Decision making, problem solving and critical thinking}

The first critical cross-field learning outcome is that learners should be able to identify and solve problems by using critical and creative thinking skills (SAQA Act, Act no 58 of 1995). Problem solving is a process of developing, testing and evaluating a method for overcoming an obstacle by identifying a problem or obstacle and stating the best alternative to solve the problem or overcome the obstacle. It is important that the learner is able to articulate the reasoning behind the order of selecting the alternatives and the extent to which each alternative solved the problem or overcame the obstacle. Learners should recognize that problem solving context do not exist in isolation (Van der Horst \& MacDonald, 1997:229). It is imperative that teachers encourage learners to solve problems in authentic, real life situations so that they can make use of their preconceived ideas, thoughts and feelings. They should be able to reflect on their previous knowledge and skills and make meaningful connection with the new knowledge to gain new insight.

Decision making, on the other hand, is a process of choosing among alternative actions the best one in order to produce the desired goal. The learner should select appropriate and important criteria with which to assess the identified alternatives in making the decision (Van der Horst \& McDonald, 1997:228). Decision making is the end product of applying critical thinking skills and scientific reasoning in problem solving resolution. Having to make a decision one has to go through the six-phase cycle of problem identification, gathering information, generating, testing, evaluating conclusions and reaching decisions. During problem solving, one recognizes that a problem exists. One then collects data, analyze it and state the problem. One will generate and select solutions, put the solution into effect and evaluate the results (Wilkinson, 1992:8). Whenever a problem cannot be solved robotically, critical thinking is required. First, one will determine the nature and dimension of the problem, and then, in the light of the first step, determine the considerations, point of views, concepts, theories and reasoning relevant to its solution. Problem solving process may not be rigidly followed in steps as literature indicates, for example, 'statement of the problem' since it is rare that problems can be precisely and fairly stated prior to analysis, gathering of evidence, and dialogical or dialectical thought wherein several provisional description of the problem are proposed, assessed and revised. Extensive practice in independent problem-solving is essential to develop critical thought.

Decision making and problem solving are closely related since one could argue how the facts ought to be considered and interpreted and how to determine their significance. A reasonable person solves problems or settles questions about what to do or believe by adjusting own thinking to the nature of each problem. If reasonable doubts can be raised about the accuracy, the depth, relevance, completeness or implications of the information, they are raised because critical thinking has to do with intellectual standards and criteria (Paul, 1993:336). This activity is in accordance with critical thinking skills of sensing problems, observing, analyzing and interpreting facts, considering all factors, deferring judgment, discovering new relationships and ideas, making inferences, evaluating consequences, developing action plans and developing feedback systems (Bandman \& Bandman, 1988:137; Paul, 1993:336, 483; Beyer, 1988:297). It is thus 
important that teachers think about and explore a variety of teaching and learning strategies to promote effective problem solving and decision making process to prepare learners for the future through OBE approach (Vand der Horst \& McDonald, 1997:50).

Problem-based learning and portfolios are examples of such teaching strategies to develop problem solving and decision making skills. The methodology of problem-based learning assists learners in acquiring integrated body of knowledge, and assist in the development or application of clinical reasoning skills. This method of teaching and learning involves the introduction of a problem in a way similar to its presentation in a real clinical world. Learners work with a problem in a manner that encourages reasoning abilities and a systematic, problem solving approach to manage real life difficulties. The applied knowledge is challenged and evaluated, resulting in the identification of individualized learning needs and directed for further study. The skills and knowledge acquired are applied back to the problem in order to evaluate the effectiveness of learning. The new knowledge gained through work with the problem and in self-directed study is summarized and integrated into the learner's existing knowledge and skills. The philosophical foundations for the problem-based learning is focused on the learner as a constructor of own knowledge, self-directed learning, critical thinking and the role of the teacher as facilitator, guider and mediator (Byrne, 1996:2). Portfolios are seen as tools to assist learners to develop critical, reflective and creative thinking abilities. Portfolios are seen as having the potential to be powerful tools for developing the learner's autonomy in learning. Through portfolios, the learner's critical awareness and knowledge of self can be nurtured, supported and developed by a skillful facilitator with positive regard for the young learner (Jenkinson, 1997:60).

\section{Emotional intelligence and critical thinking}

Emotional intelligence can be conceived as a measure of the degree to which a person successfully (or unsuccessfully) applies sound judgment and reasoning to situations in the process of determining an emotional or feeling response to those situations. It would entail the bringing of cognitive intelligence to bear upon both positive and negative emotions. It would be a measure of the extent to which our affective response was "rationally" based. Goleman (1998:317) defines the term 'emotional intelligence' as the capacity for recognizing our own feelings and those of others, for motivating ourselves, and for managing emotions well in our relationships. Emerging naturally out of rational emotions would be reasonable desires and sensible behavior. There is a close relationship between critical thinking and emotional intelligence in that critical thinking provide the mental tools needed to explicitly understand how reasoning works and how those tools can be used to take command of what we think, feel, desire and do.

Through critical thinking we acquire a means of assessing and upgrading our ability to judge well. It is critical thinking that empowers us to go into virtually any situation and to figure out the logic of whatever is happening in that situation. It provides a way for us to learn from new experiences through the process of continual self-assessment. Critical thinking then, enables us to form sound beliefs and judgments and, in so doing, provides us with a basis for a rational and reasonable emotional life. Feelings are products of thinking, and through thinking feelings can become altered. A relaxed atmosphere with humor will facilitate critical thinking and helps offset the fear of the assessment and evaluation situation. Brookfield (1987:231,232) contends that emotions are central to critical thinking. Most nurse learners are still in the 'turbulence' of adolescence. They are going through a traumatic crisis period. A period that is full of emotional instability where learners are still searching for their identity. This period is characterized by considerable physical, psychological, intellectual and emotional development that may critically affect the development of the learner's self-concept (Jenkinson, 1997:59).

Subjecting learners to assessment in a tense atmosphere may produce anxiety, fear, resentment and feelings of being threatened or intimidated. They may lead to emotional outbursts as the assessor prompt the learner to think critically. While the assessment activities blended with humor may be accompanied by feelings of liberation, release, relief, encouragement and joy predisposing the learner to think critically. The vital role of the teacher as facilitator in giving the learners support, guidance, counseling, empathizing, giving respect and encouragement cannot be overestimated or overlooked. Facilitating critical thinking is strengthening emotional intelligence of learners so that they can be guided through to acquire an identity and develop a sense of purpose that will enable them to proceed with their careers and at the same time become reflective practitioners (Jenkinson, 1997:61; Linda, 1997:40; Katz, 1998:50; Hayden-Miles (2002:421); Davis \& Stankov, 1998:989; Goleman, 1998: 37, 313). According to most advocates of critical thinking, no neat set of recipes can foster critical thinking in learners but a balance of integrating the cognitive, affective dispositions and emotional intelligence is recommended (Paul 1993:376).

\section{Recommendations}

It is recommended that research be conducted focusing on how these higher order thinking skills can be facilitated during instruction and how they can be assessed in class and/or in the clinical setting. It is advocated by literature that the assessment instruments should be validated before use for quality assurance (Glen \& Jamieson, 1993:165; Larry; Dyser \& Elliot, 2000:8; Shabir, 2004:210; Saunders, 1985; Kyriakides, 2004:143; Boudreau et al, 2004) The validation process should involve all stakeholders in a specific field. The research may be qualitative, quantitative or mixed methods in nature.

\section{Conclusion}

The paper discussed the higher order thinking skills competencies required from graduates of an outcomes-based education programme in preparing learners for the future working world. Aspects of critical thinking such as: the definition of critical thinking, its uses, significance and the philosophical foundation was discussed. The relationship of critical thinking and other competencies such as reflective thinking, creative thinking, dialogic / dialectic thinking, decision making, problem solving and emotional intelligence and their implications to teaching and learning were also discussed. These competencies will enable learners to be life long learners. Both teachers and learners are faced with the challenge of engaging and viewing these 
competencies as more propedious (towards growth), valuable, nurturing and enjoyable. Teachers need a solid philosophical commitment to producing learners who will meet the future with knowledge, skills, critical and positive attitude and values of social awareness and respect. Outcomes-based education is a flexible and relevant curriculum guided by the following principles: integration, relevance, credibility, coherence, flexibility, quality, legitimacy, access, progression, portability, articulation, recognition of prior learning, guidance of learners, democratic participation and equality of opportunities. Critical thinking, reflective thinking, creative thinking, dialogic/dialectic thinking, problem solving, decision making and emotional intelligence act as the glue to all the principles of outcomes-based education as an integral approach to the education system of the country.

\section{REFERENCES}

ALFARO-LeFeVre, R 1999: Critical thinking in nursing. A practical approach. Second edition. Philadelphia: WB Saunders.

AUSUBEL, DP 1968: Educational psychology. A cognitive view. London: Holt, Rinehart and Winston, Inc.

BAILIN,S; CASE, R; COOMBS,JR \& DANIELS, LB 1999: Conceptualizing critical thinking. Curriculum studies. 31 (3): 285-302.

BANDMANN, L \& BANDMANN, B 1988: Critical thinking in nursing. New York: Appleton \& Lange.

BECKIE, TM; LOWRY, LW \& BARNETT, S 2001: Assessing Critical Thinking in Baccalaureate Nursing Students: A Longitudinal Study. Holist Nurs Pract. 15(3); 18-26. Aspen Publisher, Inc.

BEYER, BK 1988: Developing a thinking skills program. United State of America: Allyn and Bacon.

BOUD, D; KEOGH, R \& WALKER,D 1985: Reflection: Tuming experience into learning. London: Routledge and Kegan Paul.

BOUDREAU, SP; McELVAIN, JS; MARTIN,LD; DOWLING, T \& FIELDS, SM 2004: Method validation by phase of development: An acceptable analytical practice. Pharmaceutical Technology. Cleveland: November, 2004, vol 28 (11), 54-60.

BOYD, EM \& FALES, AW 1983: Reflective learning: Key to learning from experience. Journal of Humanistic Psychologv. 23 (2): 99-117.

BROOKFIELD, S 1987: Developing critical thinkers. Open University: Milton Keynes.

BYRNE, C 1996: Problem based learning in nursing, one path to our future. Paper presented as keynote address at the University of the Witswatersrand, Johannesburg on August the 16 1996.

CHABELI, MM 2001: A model to facilitate reflective thinking in clinical nursing education. DCUR THESIS. Johannesburg: Rand Afrikaans University.

CHABELI, MM 2001: Alternative methods for clinical nursing assessment and evaluation. Health SA Gesondheid. (6) $3: 18-30$

CRESWELL, JW 1994: Research design: qualitative and quantitative approach. London: Sage Publishers.

DAVIES, M \& STANKOV, L 1998: Emotional intelligence: In search of an elusive construct. Journal of Personality and Social Psychology. 75 (4): 989-1015.

DEWEY, J 1933: How we think. A restatement of the relation of reflective thinking to the educative process. Lexington, Massachusetts.

\section{DICTIONARY OFPHILOSOPHY,1981.}

EDWARDS, S 2003: Critical thinking at bedside: a practical perspective. British Journal of Nursing. 12(19): 1142-1149.

ENNIS, RH 1985: A logical basis for measuring critical thinking skills. Educational Leadership. October, 44-48

FACIONE, PA 1998 (UPDATE): Critical thinking: what it is and why it counts. The California Academic Press, Millbrae, CA. California.

FACIONE, PA \& FACIONE, NC 1996: Externalizing the critical thinking in knowledge development. Nursing Outlook. 44(3), May/June, 1996:129-135.
FACIONE, PA; SANCHEZ, CA; FACIONE, NC \& GAINEN, J 1995: The disposition toward critical thinking. Journal of General Education. 44 (1): 1-25.

FACIONE, PA 1990: Critical thinking: A Statement of Expert Consensus for Purposes of Educational Assessment and Instruction. Executive Summary "The Delphi Report" Millbrae: California Academic Press.

GLEN, S \& JAMIESON, I 1993: The validation event: a critical appraisal. Nurse Education Today. 13:161-166

GOLEMAN, D 1998: Working with emotional intelligence. Suffolk: Clays Ltd.

GRAVETT, S 2001: Adult learning: Designing and implementing learning events - a dialogic approach. Pretoria: Van Schaik Publishers.

HAYDEN-MILES, M 2002: Humor in clinical nursing education. Journal of Nursing Education. 41 (9): 420-425.

KAMIN,CS; O'SULLIVAN,PS; YOUNG, M \& DETERDING, R 2001: Measuring critical thinking in problem-based learning discourse. Teaching and Learning in Medicine 13(1):27-35

KATZ, M 1998: Emotional intelligence. Peoples Dynamics, August, p 50.

KYRIAKIDES, L 2004: Investigating validity from teachers' perspectives through their engagement in large-scale assessment: The Emergent Literacy Baseline Assessment project. Assessment in Education. Abingdon: July 2004. vol 11 (2): 143

IGNATAVICIUS, DD 2001: Six critical thinking skills for at-the-bedside success. Nursing Management. 32 (1):37-39.

JENKINSON, T 1997: Adolescents as reflective practitioners: implications for nursing education. Nursing Education Todav. vol 17 : 58-61.

LARRY, DYSERT \& BRUCE, ELLIOT 2000: The estimate review and validation process. AACE International Transactions. Morgantown: 2000, p ES4A -ES4F.

LINDA, E 1997: Critical thinking: The key to emotional intelligence. Journal of 
MOUTON, J 1996: Understanding social research. Pretoria: JL van Schaik.

NIEBUHR, GA 1996: Lifelong learning through a National Qualifications Framework: A discussion document. Pretoria.

OERMANN, M 1999: Critical thinking, critical practice. Nursing Management. April, 30(4):40C-40I

OERMANN, M 1998: How to assess critical thinking in clinical practice. Dimensions of critical care nursing. 17 (6): 322-327.

OERMANN, M; TRUESDELL, S \& ZIOLKOWSKI, L 2000: Strategy to assess, develop and evaluate critical thinking. The Journal of Continuing Education in Nursing. July/August, 31 (4): 155-160.

QUINN, FM 2000: Principles and practice of nurse education. United Kingdom: Nelson Thornes Ltd.

PAUL, R 1993: Critical thinking: What every person needs to survive in a rapidly changing world. Foundation for critical thinking, Santa Rosa.

PETERS, M 2000: Does constructivist epistemology have a place in nursing education? Journal of Nursing Education 39(4): 166-172).

PIAGET, J 1954: The construction of reality in the child. New York: Basic Books.

SALE, D 1997: Assessing specific types of thinking in Problem-Based Learning activities. A paper presented in the $7^{\text {th }}$ International Conference on thinking in Singapore, June, 31997.

SAUNDERS, C 1985: Model Validation: The missing process. Journal of Svstems Management. Cleveland. August 1985. $\operatorname{vol}(36(8)$ : 26-29.

SHABIR, GA 2004: A practical approach to validation of HPLC methods under current good manufacturing practice. Journal of Validation Technology. New York. May 2004. vol 10(3): 210.

SOUTHAFRICA (REBUBLIC). 1996: National education policy Act 1996 (Act No. 27 of 1996), Norms and Standards for
Educators published in 4 February 2000. Government Gazette. Pretoria.

SOUTH AFRICA (REPUBLIC) 1995: South African Qualification Authority Act (Act 58 of 1995) Pretoria: Government Printers.

SPELIC, SS; PARSONS, M; HERCINGER, M; ANDREWS, A; PARKS, J \& NORRIS, J 2001: Evaluation of critical thinking outcomes of a BSN program. Holist Nurs Prct 2001; 15(3): 27-34. Aspen Publishers, Inc.

STAIB, S 2003: Teaching and measuring critical thinking. Journal of Nursing Education. November, 42 (11):498-509.

\section{THELITTLE OXFORDDICTIONARY 1986}

THEWORLDBOOKENCYCLOPEDIA 1995, VOLUME 1, 15, 18.

VANDER HORST, H \& MCDONALD, R 1997: Outcomes-Based Education: a teacher's manual. Pretoria: Kagiso.

VYGOTSKY, LS 1963: Learning and mental development at school age. Cambridge, MA: MIT Press.

WILKINSON, JM 1992: Nursing Process in action. A critical thinking approach. New York: Addison-Wesley Nursing. 